\title{
Ensino Fundamental de 9 anos: estamos preparados para implantá-lo?
}

\author{
Doralice Aparecida Paranzini Gorni
}

\section{Resumo}

A revisão da história do desenvolvimento da educação brasileira ao longo do séc. $X X$ permite-nos observar que grande parte das alternativas implantadas com o intuito de resolver os problemas de democratização, acesso e permanência do aluno em uma escola de qualidade foram suplantadas por políticas de caráter econômico e financeiro que acabavam preterindo os aspectos pedagógicos. Com base nesta constatação, entendemos que a atual proposição de ampliação do Ensino Fundamental de 8 para 9 anos representa uma nova oportunidade para a revisão deste procedimento histórico no âmbito da sociedade brasileira. Tendo em vista que o prazo proposto para adequação de todas as escolas à lei é 2010, realizou-se uma investigação junto a 2 (dois) Núcleos Regionais de Ensino, 8 (oito) Secretarias Municipais de Educação e 12 (doze) escolas vinculadas a estes órgãos, localizadas em diferentes cidades e regiões do estado do Paraná-Brasil, com o objetivo de investigar como a referida proposta chegou às escolas, bem como de que forma as mesmas estão se preparando para este processo. Para tanto, foram realizadas entrevistas junto a representantes dos núcleos e secretarias e também, junto aos diretores e professores das escolas. Podese constatar que muito pouco se sabe acerca da proposta de Implantação do Ensino Fundamental de 9 anos e que pairam muitas dúvidas e preocupações sobre se a proposta não consiste somente em mais uma mudança política e estrutural, se não significa, apenas, uma antecipação da alfabetização que poderá prejudicar as crianças. Assim sendo, parece ficar evidente a precocidade da implantação de forma ampla e generalizada, antes que sejam garantidas as condições de preparação das respectivas escolas e professores.

Palavras-chave: Ensino Fundamental de 9 anos. Políticas educacionais. Qualidade da educação. Educação básica.

\section{Abstract}

Nine-year elementary teaching: do we have the means to introduce it?

The literature review on the development of the Brazilian education along the $20^{\text {th }}$ century allows us to observe that great part of the alternatives introduced with the objective of solving problems regarding democratization, access and 
the student's permanence in a school of quality was superseded by policies of economic and financial character which ended up neglecting pedagogic aspects. Based on that, we understood that the current proposition of amplification of the Elementary Teaching from 8 to 9 years, poses a new opportunity for the review of this historical procedure in the sphere of the Brazilian society. Keeping in mind that the period proposed for schools to adapt themselves to such a law is 2010, we carried out a survey in two Regional Teaching Centers, eight Municipal Departments of Education, and twelve schools linked to such institutions, located in different cities and areas of the state of Paraná-Brazil, with the objective of investigating how the aforementioned proposal got to the schools, as well as to principals and teachers. Therefore, interviews were carried out at those regional teaching centers and municipal departments of education and also with principals and teachers of the schools at issue. It can be verified that very little is known about the proposal to introduce the 9-year Elementary Teaching and that a lot of doubts and concerns persists around that matter, namely, whether it does not consist of just another political and structural change or an anticipation of the literacy process which could be harmful to children. Thus, the prematurity of introducing such a proposal in a wide and general way is made evident before any condictions in terms of adaptation of schools and teachers themselves are garanteed.

Keywords: Elementary teaching.

Educational policies. Quality of the education. Basic education.

\section{Resumen}

Enseñanza fundamental de 9 años: ट̇es que nosotros preparamos para implantarlo?

La revisión de la historia del desarrollo de la educación brasileña a lo largo del siglo XX permítenos obsenvar que la gran parte de las alternativas implantadas con el objetivo de resolver los problemas de democratización, acceso y permanencia del estudiante en una escuela de calidad fue suplantada por políticas de carácter económico y financiero que resultaran em lo desprecio de los aspectos pedagógicos. Con base en este hecho, nosotros entendemos que la proposición actual de amplificación del la Enseñanza

Fundamental de 8 para 9 años, representa una nueva oportunidad para la revisión de este procedimiento histórico en la sociedad brasileña. Considerando que el periodo propuesto para la adaptación de todas las escuelas a la ley es 2010, nosotros efectuamos una investigación a 2(dos) Núcleos Regionales de Enseñanza, 8(ochot) Secretarías Municipales de Educación y 12(doce) escuelas vinculadas a estos órganos, localizados en ciudades y áreas diferentes del estado de ParanáBrasil, con el objetivo de investigar como tal propuesta llegó a las escuelas, así como éstas están preparándose para este proceso. A eso fueran efectuadas entrevistas com representantes de los núcleos y secretarías además de directores y maestros de las escuelas. Puédese verificar que muy poco es conocido acerca de la propuesta de implantación de la Enseñanza Fundamental de 9 años y que hay todavía muchas dudas y 
preocupaciones acerca de eso, como si la propuesta simplemente no consiste en más un cambio político y estructural, si no significa, solamente, la anticipación de la alfabetización que podrá prejudicar a los niños. Por lo tanto, parece estar evidente la precocidad de la implantación de una manera amplia y general, antes que se garanticen las condiciones de preparación de escuelas y maestros.

Palabras clave: Enseñanza

fundamental de 9 años. Política

educativa. Calidad de educación.

Educación básica.

\section{Sobre as intenções...}

Este item tem como proposição inicial tratar das "intenções". Em especial, daquelas contidas nas proposições oficiais de ampliação do Ensino Fundamental - EF, e na pesquisa relatada. Mediante tal procedimento, pretende-se alcançar o propósito secundário de provocar a 'intenção' de um novo modo de agir, comprometido com a alteração dos textos e contextos, no cenário educacional.

Tomando como ponto de partida para nossa análise a lei $n^{\circ} 11.274$ (BRASIL, 2006), sancionada em 6 de fevereiro de 2006, que dispõe sobre a duração de 9 anos para o Ensino Fundamental, com matrícula obrigatória a partir dos 6 (seis) anos de idade, podemos observar que a mesma veio consolidar a proposição de expansão deste nível de ensino, contida na Lei de Diretrizes e Bases da Educação Nacional, Lei n. 9.394 (BRASIL, 1996), e no Plano Nacional de Educação - PNE, Lei $\mathrm{n}^{\circ}$. 10.172 (BRASIL, 2001).

Tal proposição, em pleno desenvolvimento da reforma da educação brasileira iniciada nos anos 90, tanto pode significar uma tendência positiva de existência de um movimento de busca de aprimoramento do processo em desenvolvimento, quanto apenas a ocorrência de mais uma ação pontual de cunho político, com vistas a introduzir uma simples mudança estrutural que pouco ou nada vai interferir na qualidade da educação ofertada neste nível de ensino.

A medida em que uma ou outra das possibilidades vai ser alcançada depende, em grande parte, da maneira como a proposta chegue às escolas e seja nelas apreendida, analisada e, em decorrência, implementada. Assim, o processo de conscientização, envolvimento e comprometimento dos educadores que atuam nas diferentes instâncias educacionais com a concretização desta proposta deve ser o grande diferencial para que a mesma produza bons resultados.

Entretanto, tendo em vista o modus operandi que predomina no contexto nacional e no sistema educacional brasileiro desde o início do séc. $X X$, no que tange à introdução de inovações no campo educacional, como bem descrevem Ghiraldelli Júnior (2000) e Saviani $(1997,2000)$, podemos antever que a proposta em questão, a exemplo do que também já ocorreu com outras que a antecederam, tanto pode melhorar, como não alterar e até mesmo piorar o desempenho do sistema educacional, caso não receba o tratamento adequado em sua implementação.

Esta afirmação deve-se ao fato de que se a mudança consistir apenas em uma mudança estrutural, a tendência é que apenas se antecipe em um ano a idade de ingresso no Ensino Fundamental. E, neste sentido, a simples antecipação da idade escolar poderia significar a supressão de uma etapa de trabalho importante, que hoje se 
realiza no âmbito da Educação Infantil - El, e que focaliza o desenvolvimento da criança enquanto indivíduo e ser social. Não bastasse isto, também consistiria na perda de uma conquista social cuja consolidação se iniciou com a promulgação da Constituição Federal de 1988 (BRASIL, 1998).

Por outro lado, se o ingresso aos 6 anos for entendido apenas como a alteração do tipo de escola que a criança freqüenta, de forma que se mantenha inalterado o trabalho que se desenvolve junto à mesma, a situação e os atuais obtidos provavelmente se manteriam.

Do exposto acima se depreende que o elemento diferencial é a priorização do componente pedagógico e a construção de uma base de sustentação sólida sua concretização nas escolas.

No que se refere aos riscos apontados anteriormente, ambos parecem ter sido considerados na elaboração dos documentos que orientam a ampliação do EF. Entretanto, dadas as dimensões do sistema educacional brasileiro, o maior problemas que tradicionalmente enfrentamos é a materialização das propostas no âmbito das escolas. Disto decorre que o elemento mais forte que subsidia e justifica a proposição de um projeto, uma proposta ou lei, é o que primeiro se fragiliza, quando tentamos passar do nível da proposição ao da ação.

Assim, apesar da indicação de preservação do trabalho realizado na El no documento que estabelece as orientações gerais para a implantação do EF-9 anos, o risco de sua supressão também parece iminente quando consideramos os argumentos que se referem à 'oficialização' da situação que já ocorre em um número signi- ficativo de escolas, e à intenção de alinhamento da educação brasileira à dos demais países que adotam tal medida. Esta afirmação se deve a que, embora politicamente corretos, estes argumentos denotam um enfoque mais estrutural e políitico que pedagógico e, sozinhos, não oferecem base para o 'enfrentamento' do problema da 'qualidade' da educação ofertada à população nas escolas públicas.

Em decorrência, torna-se ainda mais evidente a necessidade de se atentar ao modo pelo qual vai ser viabilizada a materialização desta proposta no sistema educacional, ou seja, no contexto de cada escola.

Pelo anteriormente exposto, uma proposição da antecipação da idade para ingresso no EF requer, no ponto de partida, não apenas a indicação da necessidade de debates, estudos e discussões intra e inter os dois níveis do sistema educacional envolvidos na mudança, ou seja, El e EF, com vistas à construção de um 'diagnóstico circunstanciado' da realidade institucional e de um levantamento e avaliação das condições e perspectivas de sua implementação em cada contexto, no prazo legal estabelecido, ou seja, até 2010 . Tão ou mais importante que esta é a provisão de condições concretas para que tal processo possa ser desenvolvido pelas diferentes instâncias do sistema.

Neste sentido, cabe destacar que, embora o documento que trata das orientações gerais aponte, adequadamente, alguns caminhos que devem ser percorridos coletivamente no interior das escolas e demais instâncias do sistema educacional antes da implementação da proposta, cabe-nos indagar se: 1) este processo não deveria anteceder e, portanto, subsidiar a decisão de implantação da proposta e o estabelecimen- 
to do prazo legal para que a mesma se concretize? 2) as necessidades apontadas pelas escolas não deveriam ser sanadas a priori para que tivéssemos maiores chances de obter os resultados almejados?

Estes questionamentos se devem ao fato de que um número significativo de estados e municípios já aderiu e continua aderindo à ampliação do EF, segundo o Ministério da Educação (BRASIL, 2004). Qual o significado destas adesões? Estamos tão mobilizados e engajados nas discussões que já nos sentimos prontos para tal mudança? Quem sabe até, algumas escolas e respectivos professores já possuam todas as condições para assumir tal trabalho, mas será este o caso de todas as escolas que já fizeram sua adesão? Estamos, de novo, sendo movidos pelo impulso de 'largar' na frente, mesmo correndo o risco do ônus de não chegar ao lugar pretendido ou a lugar algum? Estamos todos conscientes de que não se trata de uma prova de velocidade e que, ao contrário, deveria ser uma ação deliberada e planejada, em que não importa sair ou chegar primeiro, mas chegarmos a um mesmo ponto, de preferência juntos e na melhor condição possível, para uma largada coletiva da educação rumo a tempos melhores?

Sob este enfoque, a Implantação do Ensino Fundamental de 9 anos pode representar, acima de tudo, uma nova alternativa traçada com o objetivo de buscar a melhoria da qualidade da educação. Diante deste fato, não podemos deixar de lembrar que nas últimas décadas, outras alternativas foram implementadas com este mesmo intuito. Dentre elas, vale a pena destacar a implantação do Ciclo Básico de Alfabetização - CBA, que foi um marco muito importante, principalmente por propor uma nova concepção de alfabetização, conforme destacado por Gorni (1999).

Além desta, também tiveram impacto significativo no contexto das escolas: a promoção automática que ampliava o tempo de aprendizagem do aluno ao eliminar a possibilidade de retenção ou reprovação após cada série; os programas de aceleração de aprendizagem ou correção de fluxo para as turmas de multirrepetentes e, mais recentemente, o programa bolsa-escola que procurou garantir acesso e permanência das crianças na escola atrelando freqüência escolar à renda familiar.

Potencialmente, cada uma destas proposições representou, em um determinado tempo e espaço, uma possibilidade de traçar novos rumos e resgatar a histórica dívida social brasileira para com uma grande parcela de sua população. No entanto, análises posteriores às mesmas, a exemplo das que encontramos em Sanzovo (2000); Munhoz (2002) e Gomide (2004), nos permitem observar que em todas ocorreram erros e acertos, que precisam ser analisados para que sejam superados alguns obstáculos presentes no sistema e para que possamos delinear outros caminhos que nos permitam construir uma sociedade mais democrática e menos desigual. Diante disto, cabe indagar: existe algum 'elemento novo' que denote a existência de uma 'outra intenção' na proposição e concretização do EF de 9 anos?

Tendo em vista este questionamento e a convicção de que mais que criticar posteriormente é preciso refletir e analisar a priori a situação, incentivar o debate e alertar as diferentes instâncias do sistema educacional e da sociedade para que o EF de 9 anos se concretize com melhores condições, surgiu a motivação para a realização do trabalho aqui relatado.

Por outro lado, a investigação realizada também objetivou recolocar em pauta a 
reflexão acerca da distância entre o que se idealiza e se concretiza em nosso país, já apontada por Saviani (1997), e que não se deve apenas à distância concreta e real existente entre quem idealiza e quem concretiza as ações, mas também e principalmente, à forma como as propostas são elaboradas, discutidas e implementadas.

\section{Sobre a realidade...}

Provavelmente, numa tentativa de encurtamento de distância entre as intenções e a realidade, a implantação do EF 9 anos tem sido discutida com diferentes segmentos da sociedade e dos sistema educacional desde 2003 (BRASIL, 2004).

A princípio, parece que a lição de casa está sendo realizada. No entanto, ainda pairam dúvidas acerca de como os diferentes níveis do sistema estão se inserindo e sendo inseridos neste processo. Cabe ainda destacar que as orientações contidas no documento, provavelmente no intuito de respeitar a autonomia das escolas, são de cunho geral e subsidiadas nos princípios e fundamentos da proposta, requerendo um certo grau de domínio da mesma, além de um certo grau de maturidade profissional, que talvez não se encontrem em todas as escolas.

Diante disto, torna-se extremamente relevante investigar se as reflexões relacionadas às condições existentes e necessárias nas escolas estão sendo desenvolvidas para subsidiar tal processo de implantação. Além destas, devem ser consideradas questões adicionais, que vão interferir significativamente no trabalho realizado em cada escola, bem como, na qualidade do mesmo, como: 1) a razão professor-aluno em sala de aula deve permanecer a atualmente vigente na $\mathrm{El}$ ou no $E F$ ? 2) qual professor deve assumir este tra- balho: da El que já tem um certo conhecimento da clientela a ser atendida, ou o do EF habituado a trabalhar com o processo de alfabetização? 3) as escolas conhecem, com certa precisão, a demanda da comunidade que atende? 4) as escolas possuem os espaços físicos e os recursos (materiais e humanos) para atender à demanda prevista? 5) existe clareza de como será o trabalho junto às crianças de 6 anos? 6) a antecipação da idade de ingresso no EF demandará quais alterações nas séries subseqüentes deste mesmo nível de ensino? 7) como as escolas estão planejando a implantação do EF 9 anos?

Tendo em vista que o prazo legal para a adequação de todas as escolas às determinações legais é 2010 e o crescente número de adesões do EF 9 anos a cada ano, considerou-se primordial investigar como esta proposta está chegando às escolas e ali sendo tratadas e nas demais instâncias do sistema educacional, ou seja, Núcleos Regionais e Secretarias Municipais de Educação.

Com esta intenção, foi realizado um estudo preliminar no primeiro semestre letivo de 2006, na disciplina "Políticas educacionais e cotidiano escolar", ofertada no Programa de Mestrado em Educação, da Universidade Estadual de Londrina - UEL. Participaram da investigação 10(dez) alunos provenientes de diferentes cidades e regiões do estado do Paraná, que realizaram entrevistas junto a 2 (dois) Núcleos Regionais de Ensino - NREs, 8 (oito) Secretarias Municipais de Educação - SMEs, e em 2 (duas) escolas estaduais e 10 (dez) escolas municipais, vinculados aos mesmos e localizados nas cidades de origem dos respectivos alunos. Cabe destacar que o pequeno número de NRE abarcados no estudo deveu-se à municipalização das primeiras séries do EF em grande parte dos municípios. 
Tanto nos NREs como nas SMEs, foram entrevistadas as pessoas responsáveis ou indicadas por estes para falar em nome do respectivo setor. Já, no âmbito das escolas, foram ouvidas as diretoras e um(a) professor(a), escolhido(a) aleatoriamente pelos entrevistadores. Também foi critério para seleção do universo da pesquisa a aceitação e disponibilidade do(a)s entrevistado(a)s em participar do trabalho.

\begin{tabular}{|c|c|c|c|}
\hline \multicolumn{2}{|c|}{ REDE ESTADUAL } & \multicolumn{2}{|c|}{ REDES MUNICIPAIS } \\
\hline NRE & Escolas & SME & Escolas \\
\hline $\begin{array}{l}\text { 1. Reunião infor- } \\
\text { mal, Conselho Es- } \\
\text { tadual, AMOP** e } \\
\text { UNDIME } \\
\text { 2. Idem (aguarda } \\
\text { seminário em Bra- } \\
\text { sília) }\end{array}$ & $\begin{array}{l}\text { 1. Pela TV } \\
\text { 2. Pela mídia e } \\
\text { conversas infor- } \\
\text { mais }\end{array}$ & $\begin{array}{l}\text { 1. Reunião da UNDIME e } \\
\text { cadernos do MEC } \\
\text { 2. Não fui recebida } \\
\text { 3. Quando tramitava no } \\
\text { congresso, UNDIME e fó- } \\
\text { runs } \\
\text { 4. Fórum em defesa da } \\
\text { escola pública, UNDIME } \\
\text { e debates } \\
\text { 5. Internet } \\
\text { 6. AMOP_UNDIME; } \\
\text { Conselho Estadual } \\
\text { 7. UNDIME e relatórios } \\
\text { de reuniões em gestão } \\
\text { anterior } \\
\text { 8.Congresso, Seminário } \\
\text { de El e material do MEC }\end{array}$ & $\begin{array}{l}\text { 1. Ouviu comentários } \\
\text { 2. Reunião com a secreta- } \\
\text { ria em } 2004 \text {, após reunião } \\
\text { da região sul em Florianó- } \\
\text { polis-SC } \\
\text { 3.Através da Lei e SME } \\
\text { 4. Material da SME } \\
\text { 5. Site do MEC*** } \\
\text { 6. TV, jornais e site do MEC. } \\
\text { Profs. só ouviram falar } \\
\text { 7.Apostila informativa } \\
\text { 8. Informalmente } \\
\text { 9. Reuniões (2) com a SME } \\
\text { (deixou de ir por falta de } \\
\text { orientação didática) } \\
\text { 10. Reuniões da SME }\end{array}$ \\
\hline
\end{tabular}

Quadro I - Forma como os NREs e SMEs e escolas vinculadas tiveram contato com a proposta Fonte: Autor (2006).

OBS: * Para efeito de análise comparativa, as respostas dos NREs e SMEs foram alinhadas às das respectivas escolas. Este procedimento foi utilizado também nos quadros posteriores.

** AMOP- Associação dos Municípios do Oeste do Paraná.

*** As escolas 3, 4 e 5 são vinculadas à mesma SME. 
Os aspectos investigados foram: 1) Como a escola/NRE/SME teve contato com a proposta? 2) Como avalia a proposta? 3) Está-se preparando para a implantação da mesma? Como? 4) Qual a perspectiva de implantação do EF 9 anos nas escolas?

As respostas obtidas foram inicialmente apresentadas à turma, e posteriormente, tabuladas e analisadas. $\bigcirc$ Quadro I, apresentado na seqüência, concentra as informações sobre a forma como as diferentes instâncias foram informadas sobre a proposta.

Conforme relatado nas entrevistas, nos dois núcleos regionais a proposta de implantação do EF 9 anos, foi informada em reunião do Conselho Estadual de Educação -CEE, e União Nacional dos Dirigentes Municipais de Educação - UNDIME. Embora apenas em um dos núcleos tenha sido colocada a informação de que estava aguardando a realização de uma reunião em Brasília a respeito do tema, tanto as diretoras quanto as professoras das duas escolas estaduais selecionadas, relataram ter tido conhecimento da proposta pela mídia.

No que se refere às SMEs, a infor- mação chegou predominantemente pela UNDIME. Apenas uma pessoa relatou ter tido acesso à proposta pela Internet. Já no que diz respeito às escolas, as formas de contato foram diversificadas, abrangendo contatos informais, reuniões na $S M E$, materiais recebidos, mídia e site do MEC. Interessante observar que em apenas uma escola foi mencionado o conhecimento da lei.

Do exposto anteriormente, podemos afirmar que não se observa uma ação planejada, organizada e sistemática de assessoramento às escolas na implantação do $E F$ ampliado, tanto no âmbito dos NREs quanto das SMEs que compuseram o universo da presente investigação. Este fato pode ter várias explicações. Além disto, é provável que também tenham que ser analisadas as condições e necessidades existentes nessas instâncias para o desenvolvimento de um trabalho deste porte.

Ao serem indagadas a respeito da avaliação que fazem da proposta, as entrevistadas dos NREs revelaram-se receptivas e ao mesmo tempo cautelosas e preocupadas com possíveis distorções que podem ocorrer, como nos mostram o Quadro II.

\begin{tabular}{|l|l|}
\hline \multicolumn{1}{|c|}{ REDE ESTADUAL } \\
\hline \multicolumn{1}{|c|}{ NRE } & \multicolumn{1}{c|}{ ESCOLAS } \\
\hline $\begin{array}{l}\text { 1. Interessante por pressupor a inclusão, mas } \\
\text { se preocupa com a alfabetização antecipada. }\end{array}$ & 1. Antecipar a alfabetização é loucura. \\
$\begin{array}{l}\text { 2. Minuta está interessante, mas não pode } \\
\text { opinar porque não tem dados oficiais. }\end{array}$ & $\begin{array}{l}\text { 2. Não avaliam porque não tem informação } \\
\text { oficial. Pensam que é uma antecipação da al- } \\
\text { fabetização. }\end{array}$ \\
\hline
\end{tabular}

Quadro II - Avaliação da proposta de Implantação do EF 9 anos.

Fonte: Autor (2006). 
Observa-se que nos NREs há uma maior tendência de aceitação da proposta e que no âmbito das escolas predominou a preocupação com a possibilidade de ocorrer apenas a antecipação da alfabetização. Uma possível explicação para este fato é que, o nível de informação predominante nestas advém da mídia e contatos informais e não das instâncias superiores do próprio sistema.

Por sua vez, as respostas obtidas junto às SMEs apontam para a receptividade da proposta, sendo que apenas uma delas destacou que não havia tido discussão da mesma. Nas demais os argumentos são, na sua grande maioria, os mesmos contidos na proposta do MEC. Isto era de se esperar, uma vez que a maioria das secretarias municipais relatou ter tido contato com a proposta nas reuniões da UNDIME. Cabe destacar que, apenas em uma secretaria não foi possível realizar a entrevista.

De modo diverso, nas respostas obtidas junto às escolas municipais, observouse uma diversidade de opiniões, que denota a existência de posições individuais e, por outro lado, a ausência de debates a respeito do tema. Uma das entrevistadas foi bastante clara ao afirmar que não tinha informações a respeito e achava que era só mudança de nomenclatura. As opiniões das demais pessoas foram agrupadas em três categorias: a primeira dos que se revelaram "receptivos" à proposta e afirmaram que: "é oportuna por que atende a demanda"; "é válida, mas aguardo orientações"; "é boa para os pobres uma vez que ingressarão antes na escola"; "tenho expectativas positivas quanto à lei e apóio por que a escola poderá acompanhar a criança desde o início".
A segunda engloba as respostas dos que se revelam descrentes e preocupados com relação à proposta e relataram que: "tratase apenas de mudança de nomenclatura"; "deveria ter sido elaborada e estudada por profissionais, pois a antecipação pode prejudicar a criança"; "de novo vamos ter inovações que não foram objeto de debates".

Por fim, na última categoria foram inseridas as respostas que denotam preocupação e desinformação quanto à operacionalização da proposta: "é positiva, mas deve-se pensar melhor o trabalho com as crianças de 6 anos"; "o material para o pré ainda não chegou"; "este passa a ser obrigatório e com "reprova"'.

conjunto das avaliações obtidas junto às diversas SMEs e escolas municipais revela, além das diferentes opiniões que perpassam o contexto escolar, o desconhecimento e as dúvidas que pairam sobre o processo. Este fato permite-nos questionar se não seria precoce tal implantação antes que todas as questões possam ser colocadas e as dúvidas esclarecidas.

Dando continuidade à investigação indagou-se se estava sendo feita alguma preparação para a implantação do EF de 9 anos e como a mesma estava sendo realizada. As pessoas ouvidas nos dois NREs afirmaram que não estavam se preparando, pois estavam aguardando "o encontro em Faxinal do Céu" e orientações da SEED. Em relação a esta questão a resposta obtida nas escolas estaduais foi, simplesmente, não.

Diante deste fato, uma última questão foi feita a respeito de se havia alguma perspectiva de implantação da ampliação do EF na respectiva rede e escolas. A entrevistada de um dos núcleos 
afirmou que não havia e que a respeito disto aguardava o encontro de Faxinal do Céu. Já a outra entrevistada afirmou que a previsão era 2007. A este respeito também nada puderam dizer as pessoas ouvidas nas escolas estaduais.
Retornando à questão relacionada à preparação para a implantação da proposta, agora, no contexto das redes municipais, foram obtidas as respostas contidas no Quadro III.

\begin{tabular}{|c|c|}
\hline SECRETARIA MUNICIPAL DE EDUCAÇÃO & ESCOLAS \\
\hline 1. Aguardando orientação da UNDIME. & 1. Aguardando orientação da SME. \\
\hline 2. Aguardando orientação da SEED. & 2. Não. \\
\hline $\begin{array}{l}\text { 3. Sim, está encaminhando as crianças e } \\
\text { preparando professores. }\end{array}$ & $\begin{array}{l}\text { 3. Rede está acomodada, o assunto é } \\
\text { levantado em pauta, mas... }\end{array}$ \\
\hline $\begin{array}{l}\text { 4. Não há problemas de estrutura física e } \\
\text { estão aguardando informações para orga- } \\
\text { nizar o currículo. }\end{array}$ & 4. Não. \\
\hline 5. Aguardando tramitação no Senado. & 5. Iniciou curso de capacitação de $24 \mathrm{~h}$. \\
\hline 6. Não. & 6. Não há preparação específica. \\
\hline $\begin{array}{l}\text { 7. Reuniões com diretores e professores } \\
\text { (convidados). Preocupação com estrutura. }\end{array}$ & 7. Não. \\
\hline \multirow[t]{3}{*}{ 8. Não. } & $\begin{array}{l}\text { 8. Espaço físico preparado (apenas esta } \\
\text { escola). Pedagogicamente não. }\end{array}$ \\
\hline & 9. Só participou de duas reuniões. \\
\hline & 10. Não. \\
\hline
\end{tabular}

Quadro III - Preparação das redes municipais para o EF de 9 anos.

Fonte: Autor (2006).

Torna-se evidente, no quadro que as informações obtidas nas SMEs e escolas vinculadas, estão predominantemente sincronizadas e revelam a ausência de condições concretas para a implantação da proposta, bem como a necessidade de que as mesmas sejam concretamente investigadas, avaliadas e viabilizadas a priori, se o que se pretende é implantar uma estratégia com vistas à melhoria da qualidade da educação básica ofertada à população, que contribua para a equiparação das oportunidades educacionais ofertadas a todas as crianças, indistintamente. É interessante destacar também que, em sentido inverso a esta tendência, a secretaria municipal 3 alega estar fazendo a preparação dos professores, quando as escolas a ela vinculadas, ou seja, 3, 4 e 5 revelam um dado não só diferente como difuso.

Finalmente, no que se refere à perspectiva de implantação do EF ampliado nas redes municipais, o Quadro IV concentra as respostas obtidas: 


\begin{tabular}{|c|c|}
\hline SECRETARIAS MUNICIPAIS DE EDUCAÇÃO & ESCOLAS MUNICIPAIS \\
\hline 1. 2007 & 1. 2007 \\
\hline 2. Não & 2. Não \\
\hline 3. 2007 - desde 2004 encaminha crianças & $\begin{array}{l}\text { 3. Cursos ( } \mathrm{p} / \text { supervisores). Estru- } \\
\text { tura física parada. }\end{array}$ \\
\hline 4. 2007 & $\begin{array}{l}\text { 4. SME está trabalhando com os } \\
\text { professores }\end{array}$ \\
\hline 5. 2007 & 5. Não \\
\hline 6. Não tem & 6. Sabe que será implantado. \\
\hline 7. 2007 & 7. 2007 \\
\hline \multirow[t]{3}{*}{ 8. Não. Acredita que nem em $2010 \ldots$} & 8. Não tem \\
\hline & 9. 2007 \\
\hline & 10. não \\
\hline
\end{tabular}

Quadro IV - Perspectiva de implantação do EF de 9 anos nas redes municipais Fonte: Autor (2006).

Comparando-se as respostas do Quadro III e IV, podemos afirmar que, a despeito da ausência de condições, predominava, no contexto investigado até o momento em que se realizou este estudo, a intenção de implantar o EF de 9 anos em 2007.

$\bigcirc$ quadro permite observar a predominante concordância das respostas obtidas nas duas instâncias. Ou seja, três secretarias e escolas correspondentes afirmaram não ter previsão de implantação e outras três afirmaram previsão de início para 2007.

Por outro lado, as secretarias e escolas que concordaram quanto à implantação iminente alegaram no quadro anterior estar: aguardando reunião da UNDIME e SME; aguardando tramitação no Senado e não estar se preparando e, que realizou reunião com professores e professores convidados mas se preocupa com a estrutura e só participou de duas reuniões, respectivamente. Infelizmente, as respostas sinalizam a ausência de condições para a implantação da ampliação do EF em 2007, mesmo nas escolas e secretarias que já optaram por isto.

Um outro dado instigante é a contradição presente na informação obtida junto à escola 4, que no Quadro III alegou que não estava se preparando e no Quadro IV afirmou a existência de um trabalho com os professores. Mesmo que este fato possa revelar a possibilidade de existir alguma inconsistência nos dados obtidos, ele não invalida a existência de diferentes níveis de conhecimento, dúvidas e preocupações no âmbito das escolas e respectivas instâncias superiores, o que reafirma a necessidade de um investimento maciço na preparação das escolas e respectivas secretarias para a implementação do EF de 9 anos em nosso país. 


\section{Considerações finais}

É ainda tempo de observar que o universo investigado não constitui amostra estatisticamente significativa do contexto maior em que está inserido. No entanto, a plena convicção de que a realidade desvelada não está apenas circunscrita ao tempo e espaço em que se deu a investigação aqui relatada também é real. Por este raciocínio, muitas outras escolas localizadas em nosso estado e, provavelmente, noutros estados de nosso país, encontram-se em condições similares às descritas.

Esta é uma das razões que motivou a elaboração deste texto que questiona: estamos preparados para implantar o Ensino Fundamental de 9 anos? Como a proposta de ampliação do EF chegou às escolas e que mudanças provocou no seu cotidiano? Ou melhor: ela chegou às escolas e provocou alguma mudança? Infelizmente a realidade nos revela um outro fato e, ao revelálo se desvela, e nos dá uma outra razão para este estudo: a crença na possibilidade de nos inserirmos nas discussões por outros e novos caminhos que se originem nas próprias escolas e que possam nos conduzir à superação dos limites e barreiras existentes no contexto educacional e, mais que isto, que venham a 'provocar' e 'contribuir' para que as reflexões e tomadas de decisão passem também pelo contexto escolar e possam ser desencadeadas 'antes deste e de qualquer outro processo de implantação' em substituição, ao velho hábito, da crítica a posteriori, que não cabe mais em uma sociedade que pretende aprimorar-se e firmar enquanto sociedade democrática.

Se juntos (docente e discentes) pudermos, num curto espaço de tempo, realizar uma investigação envolvendo diversas ci- dades, instituições e pessoas historicamente responsáveis por fazer a educação, com certeza, poderemos fazer muito mais se integrarmos o trabalho das IES ao dos diferentes segmentos da Educação Básica.

Neste momento, não é apenas justo e necessário agradecer a cada uma das pessoas que colaboraram conosco e nos permitiram aprofundar nossas reflexões acerca das políticas educacionais e seus impactos no cotidiano das escolas, como também, aos alunos que tornaram possível esta investigação, principalmente por acreditarem que o tempo que antecede alguma mudança é também tempo de produzir conhecimento e de socializá-lo, para que possamos suscitar reflexões e discussões que nos permitam tomar decisões mais lúcidas e adequadas aos nossos objetivos e ideais.

Muito mais que confortar-nos e trazernos alguma certeza, este estudo nos incomodou e inquietou, pois confirmou nossa hipótese de que ainda não é o tempo certo. E não é o tempo certo, não por que não saibamos o que fazer, mas porque ainda não sabemos como fazê-lo da forma adequada a uma sociedade democrática.

Fica o consolo de que, em alguma medida, 'suscitamos' a reflexão e discussão desta questão no âmbito das 21 instâncias envolvidas na investigação. No entanto, gostaríamos de que mais pessoas se sentissem 'provocadas e instigadas' a refletir conosco. Por isso insisto na precocidade da implantação do Ensino Fundamental de 9 anos, enquanto as condições necessárias para tal não estiverem, de fato, asseguradas às escolas. Mas para isto não só as próprias escolas devem avaliar suas condições reais e suas ne- 
cessidades, como também devem ter a garantia de que terão o lastro dos respectivos estados e municípios para consegui-las. E isto requer, necessariamente, não só mais recursos para a educação, como também um planejamento de como as condições necessárias podem ser viabilizadas no âmbito de todo o país, dentro do prazo estabelecido como limite para o atendimento da lei.

Tal proposição implicaria transferir a edu- cação do âmbito da 'prioridade do discurso' para o da 'prioridade da ação'. E, este procedimento se fundamenta, principalmente, no argumento de melhoria da qualidade da educação e democratização do acesso e permanência na escola com vistas a reduzir as desigualdades e injustiças sociais que, por sua vez, demandam investimentos de toda ordem, o que necessariamente tem um custo, que não pode ser mínimo e é inevitável que a sociedade brasileira um dia pague.

\section{Referências}

BRASIL. Câmara dos Deputados. Projeto de Lei n. 3.675/04, de 24 de novembro de 2005. Dispõe sobre a expansão do Ensino Fundamental para 9 anos. Legislação, Brasília, DF, 2005. Disponível em: <http://www2.camara.gov.br >. Acesso em: 19 abr. 2007.

Constituição (1988). Constituição da República Federativa do Brasil: promulgada em 5 de outubro de 1988: acompanhada de disposições anteriores... 2. ed. São Paulo: Oliveira Mendes, 1998.

. Lei $n^{\circ}$. 9.394, de 20 de dezembro de 1996. Estabelece as diretrizes e bases da educação nacional. Diário Oficial [da] República Federativa do Brasil, Brasília, DF, 1996. Disponível em: < http://www.planalto.gov.br >. Acesso em: 19 abr. 2006.

. Lei $n^{\circ}$. 10.172, de 9 de janeiro de 2001. Aprova o Plano Nacional de Educação e dá outras providências. Arquivos, Brasília, DF, 2001. Disponível em: < http:/ Lportal.mec.gov.Br/arquivos/pdf/L10172.pdf>. Acesso em: 19 abr. 2007.

Lei $n^{\circ} .11 .274$, de 6 e fevereiro de 2006. Altera a redação dos artigos 29, 30, 32 e 87 da Lei $n^{\circ}$. 9.394, de 20 de dezembro de 1996, que estabelece as diretrizes e bases da educação nacional, dispondo sobre a duração de 9 (nove) anos para o ensino fundamental, com matrícula obrigatória a partir dos 6 anos de idade. Diário Oficial [da] República Federativa do Brasil, Brasília, DF, 2006. Disponível em:

<http://www6.senado.gov.Br/sicon/ExecutaPesquisaBasica.action>. Acesso em: 19 abr. 2007.

. Ministério da Educação.Secretaria de Educação Básica. Ensino Fundamental de 9 anos: orientações gerais. Brasília, DF, 2004. 
GHIRALDELLI JÚNIOR, P. História da educação. 2. ed. rev. São Paulo: Cortez, 2000. (Coleção Magistério, $2^{\circ}$ grau. Série Formação do professor).

GOMIDE, A. G. V. Bolsa Escola: limites e possibilidades de um programa implantado em Londrina. 2004. Dissertação (Mestrado)-Universidade Estadual de Londrina, Londrina,

2004.

GORNI, D. A. P. Sistema Estadual de Educação do Paraná: qualidade e avaliação. 1999. Tese (Doutorado) - Universidade Estadual Paulista, Marília, SP, 1999.

MUNHOZ, M. Uma avaliação do projeto correção de fluxo nas escolas estaduais paranaenses: um novo olhar sobre o sucesso escolar?. 2002. Dissertação (Mestrado)Universidade Estadual Paulista, Marília, SP, 2002.

SANZOVO, N. Paranaeducação e correção de fluxo: as faces da exclusão. 2000. Dissertação (Mestrado)-Universidade Estadual Paulista. Marília, 2000.

SAVIANI, D. A nova lei da educação: trajetória, limites e perspectivas. 2. ed. Campinas, SP: Autores associados, 1997. (Coleção Educação Contemporânea).

Da nova LDB ao novo Plano Nacional de Educação: por uma outra política educacional. 3. ed. Campinas, SP: Autores associados, 2000. (Coleção Educação contemporânea).

Recebido em: 18/09/2006

Aceito para publicação em: 3/10/2006 